\title{
La mala praxis médica y la vulneración del deber objetivo de cuidado
}

\section{Medical Malpractice and Violation of the Objective Duty of Care}

Jelmut Espinoza Ariza* https://orcid.org/0000-0003-0328-8858

http://dx.doi.org/10.21503/lex.v19i28.2323

* Abogado - Doctor en Derecho. Docente Universitario. Perú

Correo Electrónico: jelmut16@hotmail.com
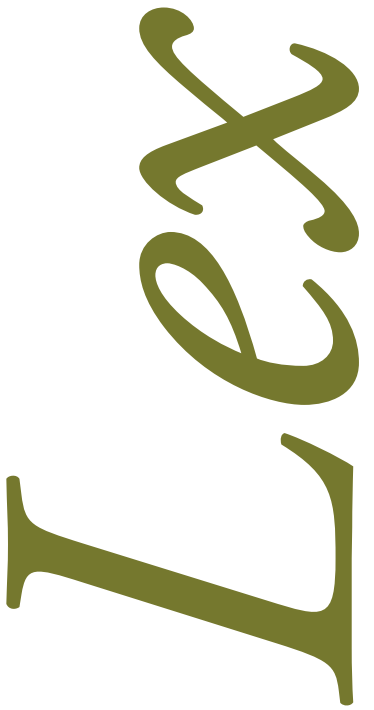

(c) (C) Los autores. Artículo publicado por la Revista Lex de la Facultad de Derecho y Ciencias Políticas de la Universidad Alas eruanas. Este es un artículo de acceso abierto, distribuido bajo los términos de la Licencia Creative Commons Atribución-No 


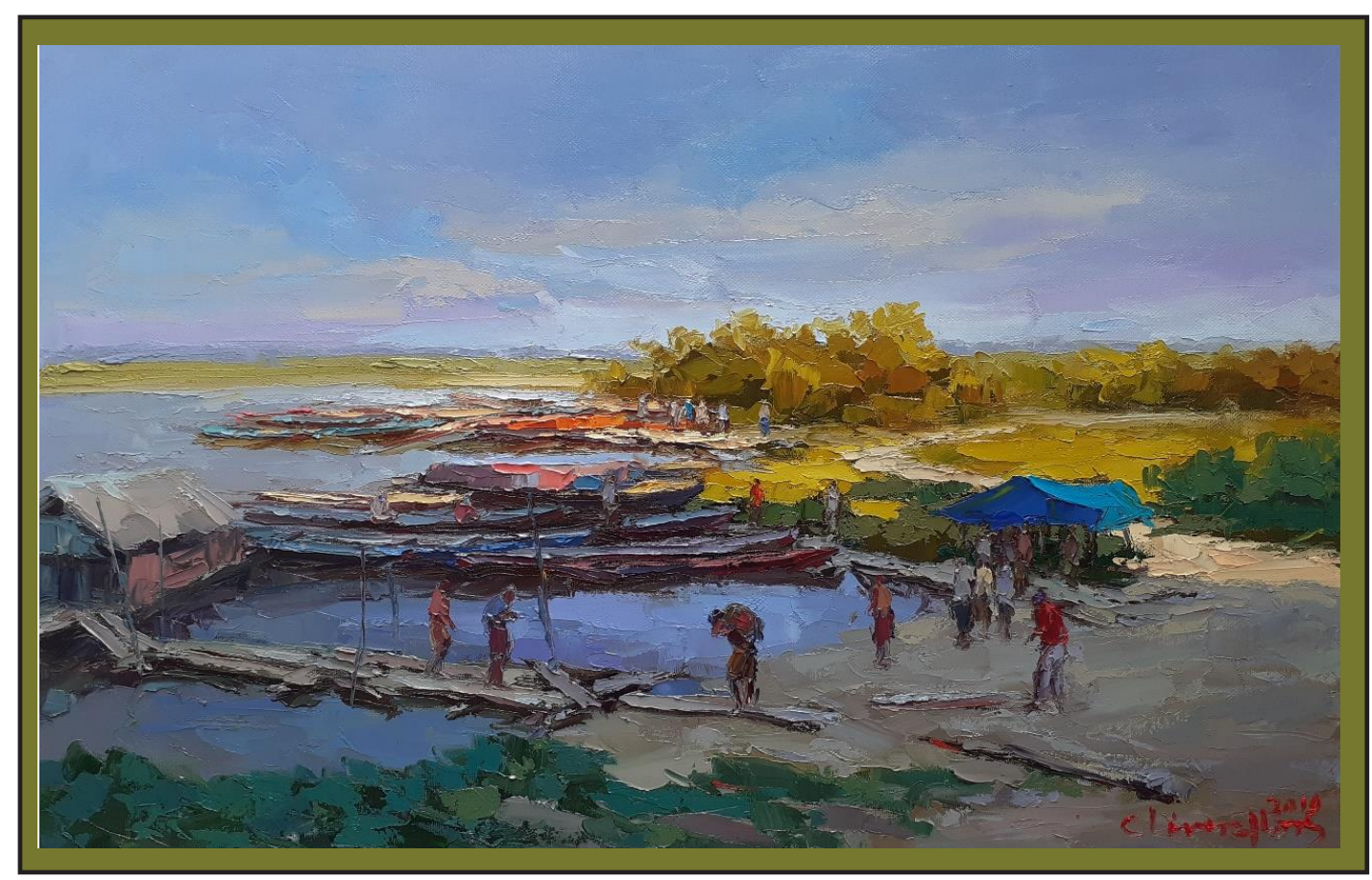

Puerto de Nanay. Óleo sobre lienzo 80 x 60 cm. (2019).

Cliver Flores Lanza (Iquitos, Loreto, Perú, 1965)

Correo electrónico: floreslanza@yahoo.com www.cliverpintoramazonico.blogspot.com 


\title{
RESUMEN
}

El presente ensayo académico pretende poner de relieve como es que la categoría "deber objetivo de cuidado" en los delitos culposos, ha contribuido a esclarecer el orden de la culpa en el delito, dado que la doctrina clásica del Derecho Penal concebía la "culpa" de forma subjetiva, que junto al "dolo" formaban parte de la culpabilidad. En tal sentido, el objetivo de la investigación es destacar que en la infracción culposa la lesión de la diligencia objetiva de cuidado no pertenece a la culpabilidad, sino a la antijuricidad; y que dicha categoría se aplica válidamente no sólo en los casos del tráfico, sino también para los casos de mala praxis médica; posición que ha sido asumida por la doctrina y jurisprudencia nacional. Al mismo tiempo, destacamos a modo de conclusión, como de manera contradictoria la jurisprudencia nacional no sólo ha asumido la concepción del deber objetivo de cuidado, sino también los criterios de imputación objetiva (creación de un riesgo no permitido) para llegar al mismo destino, que la imputación al tipo objetivo en los delitos culposos radica en la tipicidad y no en la culpabilidad.

Palabras clave: delitos culposos, deber objetivo de cuidado, imputación objetiva, mala praxis.

\begin{abstract}
The present academic essay aims to highlight how the category "objective duty of care" in culpable crimes has contributed to clarify the order of guilt in crime, since the classic doctrine of Criminal Law conceived "guilt" subjectively, which together with the "fraud" were part of the guilt. In this sense, the objective of the investigation is to emphasize that in the culpable infringement the injury of the objective diligence of care does not belong to the guilt, but to the unlawfulness; and that this category is validly applied not only in cases of trafficking, but also in cases of medical malpractice; position that has been assumed by national doctrine and jurisprudence. At the same time, we highlight by way of conclusion, how in a contradictory way the national jurisprudence has not only assumed the conception of the objective duty of care, but also the criteria of objective imputation (creation of an unauthorized risk) to reach the same destination, that the imputation to the objective rate in culpable crimes lies in the typicity and not in the guilt.
\end{abstract}

Key words: culpable crimes, objective duty of care, objective imputation, malpractice. 


\section{VULNERACIÓN AL DEBER OBJETIVO DE CUIDADO}

En términos dogmáticos, el obrar negligente dentro del marco de la lex artis se define como "falta al deber objetivo de cuidado", constituido por dos elementos: uno de carácter objetivo y otro de carácter normativo. De esta forma, en cuanto al primer elemento (objetivo), la violación al deber de cuidado objetivo se evalúa siempre dentro de un ámbito situacional determinado, es decir, por medio de un juicio de la conducta humana en el contexto de relación en el cual se desempeńó el actor. En ese sentido, habrá infracción en tanto se constate, con independencia de las capacidades individuales del médico actuante, que no se aplicó el estándar sanitario exigible en ese caso y que es el aplicado generalmente por los médicos sanitarios (baremo del cirujano medio). En lo que respecta al segundo elemento (normativo), la determinación de que una conducta es imprudente depende de parámetros que la ley sólo enuncia. El Legislador, por imposibilidad real de describir la inmensidad de conductas que pueden poner en peligro o dañar bienes jurídicos, con motivo principalmente de la industrialización y avances tecnológicos-científicos, se limita a fijar una imagen rectora que oriente al juez de modo semejante a lo que sucede en los delitos de comisión por omisión. Estamos frente a un "tipo penal abierto" que debe ser llenado por el conjunto de reglas técnicas o procedimentales suministradas por las ciencias biomédicas y aplicadas por los miembros de esa comunidad científica a situaciones ya conocidas y contrastadas; a ese conjunto de reglas se le denomina lex artis ${ }^{1}$.

Pero este elemento de la "infracción de un deber objetivo de cuidado", no siempre formó parte de los elementos constitutivos integrantes del delito culposo, más bien se trata de un desarrollo dogmático reciente, admitido hoy en día también por la jurisprudencia. En la formulación inicial de esta nueva postura, no basta que el acto culposo realizado por el autor produzca un resultado típico, el cual haya sido previsible y evitable, sino que además se conjuga con una "característica adicional, consistente en la infracción de un deber general de cuidado, impuesto por el ordenamiento jurídico en la realización de acciones peligrosas para determinados bienes jurídicamente protegidos (...); constituyendo ésta una nota restrictiva de la responsabilidad" ${ }^{2}$. Pero yendo más allá, y como consecuencia inevitable de

1. Ramiro Salinas Siccha, Derecho Penal. Parte Especial. Vol. 1 (Lima: Grijley, 2010), 103-104.

2. Ángel Torio López, "El deber objetivo de cuidado en los delitos culposos", Anuario de derecho penal y ciencias penales, 27, 1 (1974): 25. 
la formulación propuesta, Engisch entiende que ahora ya no es posible hablar de la culpa en sentido subjetivo. De esta forma, en el delito culposo no sólo se introduce la categoría de "infracción de la diligencia objetivamente debida", sino que además, "la culpa entendida de forma subjetiva, situándose al lado del dolo como modalidad alternativa de la culpabilidad"3, sufrió un desplazamiento dentro de los elementos categoriales del delito, pasando en efecto, de la culpabilidad a la antijuricidad. Engisch afirma que "la lesión de la diligencia objetiva no pertenece a la culpabilidad, sino a la antijuridicidad" ${ }^{\text {. }}$ Se produce de esta forma un cambio sistemático muy importante en la figura de la infracción culposa.

En tal sentido, para Frank, incurre en culpa, quien al aceptar realizar una acción peligrosa, como el médico que sin la adecuada preparación quirúrgica practica una intervención de riesgo, obrando culposamente respecto al resultado mortal, incluso si obró con el cuidado posible, pero que sin embargo, dada su falta de competencia, no debió aceptar el encargo 5 . De pronto, el médico actuó con atención escrupulosa, pese a ello lo hizo de manera imprudente; pues,

(...) no es que el médico haya atendido de forma insuficiente a la fuente de peligro (paciente), sino que, pese al reconocimiento del peligro, hizo algo que debió omitir, al emprender la ejecución de un acto en sí mismo peligroso. El cuidado experimenta un desplazamiento desde el lado subjetivo al objetivo: la acción del sujeto no era cuidadosa porque desde la perspectiva externa no estaba orientada a evitar la realización del tipo de homicidio ${ }^{6}$.

Quien terminó de delinear este nuevo planteamiento de la culpa como infracción al deber objetivo de cuidado, fue Hans Welzel, quien advierte que el cuidado necesario en el tráfico es un concepto objetivo y normativo. Para Welzel "una conducta responde al cuidado objetivo, si considera prudentemente los efectos de la acción planeada que sean cognoscibles en un juicio inteligente, es decir, si coincide con la conducta que seguiría un hombre inteligente y prudente en la situación del autor"

\section{CRITERIOS DE IMPUTACIÓN OBJETIVA}

Sin embargo, Roxin le da un vuelco al planteamiento anterior al introducir una nueva categoría en el esquema de la culpa. En efecto, la categoría de infracción del deber de cuidado sería imprecisa porque su interpretación sugiere de manera errónea como un delito de omisión; y lo sustituye por los criterios de imputación objetiva; según el cual al sujeto no se le reprocha el haber omitido algo, sino el haber creado un peligro no amparado por riesgo permitido y sí abarcado por el fin de protección del tipo, que se ha realizado en un resultado típico ${ }^{8}$. De esta forma, se crea un riesgo jurídicamente

3. Ibídem, p. 26.

4. Ibídem, p. 27.

5. Citado en Ángel Torio López, op. cit. p. 27.

6. Ibídem, p. 27.

7. Ibídem, p. 29-30.

8. Claus Roxin, Derecho penal, parte general, Tomo I. "Fundamentos. La estructura de la teoría del delito". Traducción y notas Diego Manuel Luzón Peña. Miguel Díaz y Gracia Conllevo. Javier de Vicente Remesal (Madrid: Civitas, 1997), 998-999. 
desaprobado cuando al elevarse el riesgo, se sobrepasa el límite de lo aceptado o permitido, para lo cual resulta relevante su examen tomando en cuenta el baremo del hombre medio, o del cirujano medio en el caso del médico. Contrariamente, no provoca un riesgo jurídicamente desaprobado quien incurre en una conducta socialmente normal y generalmente no peligrosa, no prohibida por el ordenamiento jurídico. De esta forma, para Roxin, la doctrina que más se impone ahora, es la concepción de que la imputación al tipo objetivo se produce conforme a dos principios sucesivamente estructurados:

a) Un resultado causado por el agente sólo se puede imputar al tipo objetivo si la conducta del autor ha creado un peligro para el bien jurídico no cubierto por un riesgo permitido y ese peligro también se ha realizado en el resultado concreto.

b) Si el resultado se presenta como realización de un peligro creado por el autor, por regla general es imputable, de modo que se cumple el tipo objetivo. Pero no obstante, excepcionalmente puede desaparecer la imputación si el alcance del tipo no abarca la evitación de tales peligros y sus repercusiones ${ }^{9}$.

Pero, aun hay más, pues, la imputación objetiva también ha sido objeto de críticas por diversos autores. Gimbernat Ordeig, por ejemplo, señala que aplicar la teoría del incremento del riesgo llevaría a soluciones equivocadas; y propone en su lugar el principio del "fin de protección de la norma". Este autor señala lo siguiente:

"Por lo que se refiere a los delitos culposos, la solución parte de que los deberes de diligencia, cuya infracción es lo que hace que una acción sea imprudente, persiguen impedir determinados resultados. Si el resultado producido por el comportamiento negligente no es uno de los que se querían evitar con el establecimiento de un deber, el autor estará exento de responsabilidad. Cuál sea el fin de la norma, es algo que se determina fácilmente acudiendo a los métodos corrientes de la interpretación jurídicopenal. En los delitos dolosos el procedimiento es análogo: si el resultado producido es uno de los que la norma quería evitar, el autor responderá por delito consumado" 10 .

En realidad, la teoría de la imputación objetiva implica una clarificación y, con ello, un avance en la comprensión del tipo objetivo. Pero, en líneas generales se puede afirmar que "la teoría de la imputación objetiva sólo entra en juego para excluir en última instancia la tipicidad si consta ya que un comportamiento doloso o imprudente ha causado -condicionado- el resultado típico (...)"11. Se han expuesto algunos criterios que excluyen la imputación objetiva, veamos los principales:

- El fin de protección de la norma: por este criterio si un comportamiento imprudente - o doloso- causa un resultado típico, no será objetivamente imputable y, tampoco típico, si la norma

9. Ibídem, p. 363-364.

10. Citado en Darío Alberto Dal Dosso, “Teoría de la imputación objetiva” (Investigación para la evaluación final correspondiente a la VI edición del master propio en Derecho Penal. Universidad de Sevilla: octubre/noviembre 2011), 27-28.

11. Enrique Gimbernat Ordeig, "A vueltas con la imputación objetiva, la participación delictiva, la omisión impropia y el derecho penal de la culpabilidad”, Nuevo Foro Penal, 82, enero-junio (2014): 86. 
formalmente infringida no se estableció para evitar ese resultado tal como en concreto se produjo; en otras palabras, si el resultado que se produjo cae fuera del ámbito de protección de la norma ${ }^{12}$.

- Cuando la acción dolosa causante del resultado típico es una objetivamente correcta; con este criterio se excluye aquella conducta dolosa, pero cuyo resultado típico fue realizado con un medio objetivamente correcto, como es por ejemplo, del sujeto que para matar a otra persona, la convence para que realice un viaje en avión, pagándole el pasaje, consiguiendo su propósito al estrellarse el aparato contra el suelo falleciendo todos sus ocupantes. El agente tan solo supone -un mal pensamiento- que el avión podría estrellarse, no existe la seguridad de que ello ocurra, pero ocurre ${ }^{13}$.

- El consentimiento de la víctima en el riesgo como factor excluyente de la imputación objetiva; es el caso de la víctima que consciente en el riesgo de resultar lesionada o muerta, y el riesgo en efecto, conlleva a la producción de un resultado típico; "diferenciándose entre heteropuesta en peligro consentida y participación en una autopuesta en peligro, distinguiéndose una de otra en que, mientras que en la primera es el tercero quien finalmente causa la lesión a la víctima, en la segunda es la misma víctima la que, inducida por el tercero, se autocausa su propia muerte o su propia lesión"14.

- Casos de ausencia (o de presencia) de imputación objetiva cuando entre la acción inicial dolosa o imprudente y el resultado típico final se interpone la conducta, también dolosa o imprudente, de un tercero; por este criterio si bien el acontecimiento tiene su origen en una -más o menos grave- agresión física dolosa o imprudente del autor primario, entre dicha agresión y el resultado final se interpone un tercero (un particular o el personal sanitario que atiende al herido o la propia víctima) que, dolosa o imprudentemente también, contribuye a la agravación de ese resultado o que no impide -pudiendo hacerlo- que esa agravación se produzca; por ejemplo: el herido dolosa o imprudentemente por el autor inicial fallece porque a ello contribuye también un error del cirujano que le ha intervenido quirúrgicamente ${ }^{15}$.

- Comportamiento alternativo conforme a Derecho versus teoría del incremento del riesgo; por este criterio, a pesar de que el autor imprudente ha causado el resultado típico, no obstante se mantiene la no-responsabilidad del autor cuando -según el criterio del comportamiento alternativo conforme a Derecho- el resultado también se habría producido -con certeza, aunque dicho autor hubiera actuado correctamente ${ }^{16}$.

12. Enrique Gimbernat Ordeig, op. cit. p. 87.

13. Ibídem, p. 90-91.

14. Ibídem, p. 92.

15. Ibídem, p. 94.

16. Enrique Gimbernat Ordeig, ob. cit. p. 94. En este caso, el citado autor pone el ejemplo del llamado "caso de los pelos de cabra”, en el que el dueño de una fábrica de pinceles adquirió a una empresa china pelos de cabra para elaborar sus productos, $y$, a pesar de que estaba obligado a desinfectarlos, se los entregó a sus empleadas omitiendo esa desinfección, contrayendo cuatro de ellas el bacilo de corbunco, lo que les provocó la muerte. El informe pericial puso de manifiesto, no obstante, que, aunque el empresario hubiera cumplido con su deber, las operarias tal vez habrían fallecido también, 


\section{INFRACCIÓN A LA LEX ARTIS Y EL RESULTADO LESIVO}

La sola infracción a la lex artis no es por sí misma constitutiva de delito, sino que, además, es necesario verificar que esa infracción a fue la que produjo el resultado lesivo para el bien jurídico. En este sentido, la jurisprudencia española ha establecido que no toda infracción a la lex artis es constitutiva de una infracción al deber de cuidado, siendo indispensable que la misma sea "inexcusable". Es decir, "para que la imprudencia médica sea penalmente relevante es necesario que en el tratamiento dispensado al paciente se incurra en conductas descuidadas de las que resulta un proceder irreflexivo, la falta de adopción de cautelas de generalizado uso o ausencia de pruebas, investigaciones o verificaciones precisas como imprescindibles para según el curso del estado del paciente actuar, aunque entonces el reproche de culpabilidad viene dado, no tanto por el error (si lo hubiere), sino por la dejación, el abandono, la negligencia o el descuido de la atención que aquél requiere" ${ }^{17}$.

\section{DERECHO A LA INFORMACIÓN DEL PACIENTE Y EL CONSENTIMIENTO IN- FORMADO}

El paciente tiene derecho a ser informado de todo lo relacionado con la enfermedad que padece, los posibles riesgos de la intervención, alternativas de tratamiento e incluso las precauciones después de la intervención. La Ley General de Salud -Ley No 26842, modificado por la Ley №29414 del 02-10-2009-, establece el derecho que tiene toda persona a acceder a información relacionada sobre el diagnóstico, alternativas de tratamiento, los riesgos, contraindicaciones, precauciones de la intervención, así como el tratamiento y los medicamentos que son prescritos; en otras palabras estamos hablando del "derecho a saber" del paciente, que en el artículo $15^{\circ}$ literal f) de la citada ley, señala lo siguiente ${ }^{18}$ :

f) A recibir en términos comprensibles información completa, oportuna y continuada sobre su enfermedad, incluyendo el diagnóstico, pronóstico y alternativas de tratamiento; así como sobre los riesgos, contraindicaciones, precauciones y advertencias de las intervenciones, tratamientos y medicamentos que se prescriban y administren. Tiene derecho a recibir información de sus necesidades de atención y tratamiento al ser dado de alta.

Asimismo, el Código de Ética y Deontología Médica del Colegio Médico del Perú (2007), establece en el artículo $63^{\circ}$ inciso e) lo siguiente: que el paciente tiene derecho a "aceptar o rechazar un procedimiento o tratamiento después de haber sido adecuadamente informado o a revocar su decisión en cualquier momento, sin obligación de expresión de causa”.

dado que no resultó acreditado que los desinfectantes hubieran podido destruir los gérmenes.

17. Sección $1^{\text {a }}$ de la Audiencia Provincial de Las Palmas. Sentencia núm. 257/2016; de fecha 20 de marzo de 2009.

18. El "derecho a saber" -así como el "derecho a no saber"-, se encuentran consagrados en diversos instrumentos internacionales de derechos humanos, como: la Convención europea de Derechos Humanos y Biomedicina de 1997 (“Convención de Oviedo"); las dos Declaraciones adoptadas por la UNESCO en este ámbito: la Declaración sobre el Genoma Humano y los Derechos Humanos de 1997 y la Declaración Internacional sobre Datos Genéticos Humanos de 2003. 
Desde esta perspectiva, es fundamental que el médico explique de modo simple las ventajas e inconvenientes de una u otra posibilidad diagnóstica y terapéutica, e incluso los riesgos de una posible intervención, manifestando su opinión sobre cada una de ellas. Es decir, la información debe extenderse a las características de la intervención o el tratamiento que se propone y sus beneficios, las recomendaciones, los riesgos que implica y sus consecuencias (generales y específicos del paciente atendiendo a cada situación clínica particular), las contraindicaciones y las alternativas posibles. Lo contrario supone abandonar al paciente en su desconocimiento, y vulnerar el derecho a la información que tiene el paciente para que éste pueda decidir disponiendo sobre su propio cuerpo pero con conocimiento sobre su decisión ${ }^{19}$.

En ese sentido, lo que se pone de relieve a efectos de que se configure el delito de lesiones culposas por mala praxis médica, es el daño que se produce a consecuencia de haberse omitido la información previa al consentimiento. Ahora, la falta de información no es "per se" una causa de delito y de resarcimiento pecuniario si no hay un daño derivado, evitable de haberse producido ${ }^{20}$. La experiencia del Tribunal Supremo Español sobre este asunto es muy rica y ha puesto de relieve en sus numerosos casos resueltos, cómo la falta de información, previo al consentimiento informado, genera responsabilidad civil y penal en los médicos si se produce un daño evitable, si se hubiera informado adecuadamente al paciente sobre los riesgos de la intervención y los cuidados preventivos post operatorio. Es bueno precisar que hoy en día la doctrina y la jurisprudencia entiende, en función de la especial naturaleza del servicio médico demandado y prestado, que la obligación del médico y del sanitario en general es de medios, lo que quiere decir que está obligado no a curar al enfermo sino a proporcionarle todos los cuidados que requiera según el estado de la ciencia; de esta forma, a contrario sensu, la obligación no es de resultado, pues no es responsable de la curación del paciente, a no ser que se deba a motivos imputables al mismo, o que se trate del caso de medicina satisfactiva (estética) o preventiva.

No se cuestiona lo regular y acertado del procedimiento llevado a cabo por los médicos procesados; pues, es posible que la actuación de los médicos haya sido la correcta desde lo técnico y que el resultado lesivo para el paciente haya sido previsto como un riesgo que, atendiendo a sus condiciones particulares, se desprendía del procedimiento; sin embargo, y conforme se estableció en la Sentencia del 24 de enero de 2002, del Consejo de Estado de Colombia, a modo de ejemplo, "a pesar de lo correcto del procedimiento, se estableció que dicho riesgo no había sido informado al paciente, por lo que se entiende que éste perdió la oportunidad de oponerse a la intervención generando una responsabilidad en cabeza del Estado por la cual tenía que ser indemnizado e incluso una condena a los médicos por

19. Roberto Vázquez Ferreyra, Daños y perjuicios en el ejercicio de la medicina (2 Edición) (Buenos Aires: Hammurabi, 2002), 39.

20. Sentencia de la Sala de lo Civil del Tribunal Supremo Español, de 8 de septiembre de 2015. Asimismo, cfr. Javier López García de la Serrana, "La valoración del daño por falta de consentimiento informado en la práctica médica", Revista Economist \& Jurist, (2010), acceso el 01 de agosto del 2021, https://www.economistjurist.es/articulos-juridicosdestacados/la-valoracion-del-dano-por-falta-de-consentimiento-informado-en-la-practica-medica/ 
mala praxis" 21 . Ante ello, debemos concluir que ni siquiera obrando de conformidad con la lex artis los profesionales de la salud pueden decir que han actuado correctamente, pues, a pesar de lo correcto del procedimiento, se produce una condena de mala praxis por infracción al deber de información ${ }^{22}$.

\section{EL DEBER OBJETIVO DE CUIDADO EN LA JURISPRUDENCIA NACIONAL}

Como refiere Julio Mazuelos, desde hace muchos años nuestra jurisprudencia ha asumido la posición de la doctrina mayoritaria en lo que se refiere a la exigencia de la infracción del deber objetivo de cuidado para afirmar la tipicidad del delito culposo, lo cual se refleja en diversas ejecutorias ${ }^{23}$; y aunque en un principio la definición adoptada era muy genérica al señalarse que el deber objetivo de cuidado es "el conjunto de reglas que debe observar toda persona al realizar una actividad concreta a título de profesión, ocupación o industria, por ser elemental y ostensible en cada caso como indicadores de pericia, destreza o prudencia" 24 .

Pero, de forma paradójica, en algunos casos, nuestra jurisprudencia también ha adoptado la aplicación de la teoría de la imputación objetiva en el delito imprudente ${ }^{25}$; requiriéndose en este caso para su configuración "a) el incremento del riesgo permitido [...]; b) la realización del riesgo implícito en la acción imprudente en el resultado [...]; y c) el resultado debe producirse dentro del ámbito de protección de la norma [...]"26.

En tal sentido, como bien precisa Julio Mazuelos, "la jurisprudencia no es unánime en afirmar que la infracción del deber de cuidado fundamenta el aspecto objetivo de la tipicidad del delito imprudente, pues en algunas sentencias se hace alusión a la creación de un riesgo no permitido y no a la infracción del deber de cuidado" 27 .

Pese a ello, hay que admitir que con el tiempo nuestra jurisprudencia ha perfilado una conceptualización mucho más precisa de lo que debe entenderse por infracción del deber objetivo de cuidado en el marco de los delitos culposos. Así, en reciente jurisprudencia, la Corte Suprema ha señalado ${ }^{28}$ :

21. Francisco Bernate Ochoa, Imputación Objetiva y responsabilidad penal médica (Bogotá D.C.: Universidad del Rosario, 2010), 35.

22. Ibídem, p. 35.

23. Por ejemplo: Ejecutoria Suprema R.N. 4288-97 Ancash de 13/04/1998; Ejecutoria Superior Exp. 3762-97 de 17/09/97 Sala Penal de Apelaciones - Lima. Cfr. Julio Mazuelos Coello, "El delito imprudente en el Código penal peruano. La infracción del deber de cuidado como creación de un riesgo jurídicamente desaprobado y la previsibilidad individual", Portal Anuario de Derecho Penal, (2003), acceso el 02 de agosto del 2021 https://perso.unifr.ch/derechopenal/assets/files/anuario/an_2003_09.pdf.

24. Ejecutoria Suprema R.N. 2007-97 de 02/04/199. Cfr. Julio Mazuelos Coello, op. Cit. Passin.

25. Ejecutoria Superior Exp. 5615-97 de 09/12/97 Sala Penal de Apelaciones - Lima. Cfr. Julio Mazuelos Coello, ob. Cit.

26. Cfr. Julio Mazuelos Coello, ob. Cit.

27. Ejecutoria Suprema R.N. 6239-97 Ancash de 03/06/98. Cfr. Julio Mazuelos Coello, op. cit.

28. Sala Penal Permanente de la Corte Suprema de Justicia, Casación N 581-2015 Piura; asimismo, Sala Penal Permanente de la Corte Suprema de Justicia, Casación N 153-2017 Piura, de fecha 24-04-2018. 
Para poder considerar a una persona autor de un delito culposo o imprudente se le debe imputar: la infracción de la norma de cuidado y la producción de un resultado a consecuencia de dicha infracción de la norma. Entiéndase por deber objetivo de cuidado al conjunto de reglas que debe observar el agente mientras desarrolla una actividad concreta en el ejercicio de una profesión, ocupación o industria.

En esa línea, los elementos objetivos estructurales de todo delito culposo son: a) la violación de un deber objetivo de cuidado, plasmado en normas jurídicas, normas de experiencia, normas del arte, ciencia o profesión, destinadas a orientar diligentemente el comportamiento del individuo; y, b) la producción de un resultado típico imputable objetivamente al autor por haber creado $o$ incrementado un riesgo jurídicamente relevante que se ha materializado en el resultado lesivo del bien jurídico. Es de precisar que si el comportamiento del sujeto activo adolece de algún elemento allí exigido estaremos ante un caso de atipicidad.

En esta jurisprudencia podemos observar que pese a lo preciso y claro que pretende ser, al ofrecer de manera detallada cada uno de los elementos estructurales que integra el delito culposo, sin embargo, confunde ambos sistemas de culpa, pues en un mismo concepto desarrolla "el deber objetivo de cuidado" y los criterios de "imputación objetiva", que como se ha explicitado, el primero implica un no hacer (omisión), inobservando de esta forma las reglas de profesión; mientras que el segundo implica una conducta activa, el actuar creando un peligro no amparado por riesgo permitido.

\section{ALGUNOS CASOS DE MALA PRAXIS}

Caso $1^{29}$ : El presente caso es de una gestante que ingresa al centro de salud por emergencia, y habiendo una indicación expresa por el primer médico que la evaluó, que el producto debía nacer vía cesárea, sin embargo, el segundo médico que siguió con la paciente determinó que el parto se realizara por vía vaginal, lo que conllevó que el bebé muriera, debido al trauma obstétrico al momento del parto y la hemorragia intracraneana sufrida, lo cual llevó a desarrollar encefalomalacia ${ }^{30}$. Veamos los detalles, y la evidencia que se reunió. La paciente " $\mathrm{X}$ " ingresa por servicio de emergencia del Centro de Salud en estado de gestación, es evaluada por ginecología a las 10:30 horas, no fue considerado la incompatibilidad céfalo pélvica ${ }^{31}$ al no realizarse pelvimetría ni diagnóstico por imágenes para determinar el ponderado fetal; solo a las 12:45 horas, se diagnostica la incompatibilidad céfalo pél-

29. Primera Sala Penal Liquidadora de la Corte Superior de Justicia de Lima, Exp. 5120-2018.

30. El término malacia proviene del griego antiguo "malakia" que significa, reblandecimiento. Es un sufijo utilizado para formar palabras que describen una alteración patológica de los tejidos del organismo, caracterizada por un deterioro progresivo de la consistencia normal de dichos tejidos. Cuando eso sucede en el Sistema Nervioso Central (SNC) se denomina, encefalomalacia. En general, hace referencia al ablandamiento o la pérdida de tejido cerebral causado, principalmente, por un infarto cerebral, una isquemia, una infección o un trauma. Cfr. la siguiente página electrónica: https://www.medigoo.com/es/compruebe-el-sintoma/encefalomalacia/

31. Feto grande que no podría nacer vía vaginal sino por cesárea. 
vica, y se determina que la terminación del parto debe ser por vía cesárea por emergencia, pero no se ingresó a sala de operaciones de manera inmediata. Al momento que se le realiza la ecografía se le diagnostica: 1) gesta 4 de 38 semanas por última regla; 2) trabajo de parto fase activa; 3) alto riesgo obstétrico: multigesta con control prenatal insuficiente; 4) incompatibilidad céfalo pélvica”; y como Plan de Trabajo: se señala: "cesárea de emergencia". Sin embargo, el médico de guardia que evaluó a la paciente y determinó que la gestación tenía que culminar por cesárea, no pudo seguir con la paciente al ingresar a cirugía. Otro médico se encargó de la paciente. Pero no fue atendida de forma inmediata como había prescrito el primer médico. En el interín, la obstetra de sala de emergencia le reitera que tiene que pasar a sala de operación urgente para una cesárea, porque el bebe no podía salir, por ser un bebe grande, pero luego la obstetra también le indica que en ese momento no había sala disponible, y cuando ya había sala, le indica que no había anestesiólogo. El nuevo médico, responsable ahora del parto de la paciente, sabía perfectamente del alto riesgo obstétrico y de la incompatibilidad céfalo pélvica; sin embargo, hizo esperar a la paciente durante dos horas con 22 minutos y finalmente determinó que el feto debía nacer vía vaginal. El parto debía realizarse a la 13:00 p.m., sin embargo, se realizó a las 15:22 horas, por el parto inminente ya que el bebe se encontraba saliendo por la vagina de la paciente. Luego de producida la muerte del bebe, se inició una investigación administrativa, donde el médico en sus descargos afirmó que había realizado coordinaciones a las 13:30 y 14:40 horas con el Departamento de Anestesiología para que la paciente sea intervenida quirúrgicamente, pero que no se pudo porque no había sala disponible. Pero este dicho fue desmentido por dicho Departamento, al señalarse que en ningún momento hubo tal coordinación y que cuando existen problemas de falta de personal de enfermería para la apertura de quirófano o falta de anestesiólogo, porque todos están ocupados, se da solución al problema movilizando personal de otras áreas; asimismo, el Departamento de Anestesiología informó que entre la 13:00 horas y las 15:00 horas, de las tres salas de operaciones que cuenta, sólo se utilizaron dos salas, quedando una tercera sala libre con su respectivo anestesiólogo, por lo que no resultaba cierto que todas las salas estaban ocupadas dentro de la hora que indicó el médico denunciado. Por último, el Instituto de Medicina Legal, en su pronunciamiento médico señaló que "Existe relación de causa-efecto entre el trauma obstétrico al momento del parto y la hemorragia intracraneana, lo cual llevó a desarrollar la encefalomalacia". Asimismo, determinó que la incompatibilidad céfalo-pélvica, que no fue diagnosticada oportunamente, y que la determinación de pasar a la paciente de emergencia al centro obstétrico para atención de parto por vía vaginal no fue la adecuada; pues, la atención del parto debió ser quirúrgica (cesárea).

En consecuencia, de la investigación administrativa se determinó que se habría vulnerado el Derecho al acceso a servicios, medicamentos y productos sanitarios, previsto en el artículo $2^{\circ}$ de la Ley General de Salud -Ley No 26842-, modificado por la Ley N²9414 del 02-10-2009, que establece: "Artículo 2o.- Toda persona tiene derecho a exigir que los bienes destinados a la atención de su salud correspondan a las características y atributos indicados en su presentación y a todas aquellas que se acreditaron para su autorización (...); al negársele a la paciente "X", al ingresar por servicio de emergencia del Instituto Nacional Materno Perinatal en estado de gestación, a que el parto se realice por "cesárea de emergencia", dado que existía "incompatibilidad céfalo pélvica”, produciéndose la muerte del bebe. Asimismo, se determinó que se había vulnerado el Artículo $10^{\circ}$ del Reglamento de la Ley $\mathrm{N}^{\circ}$ 
29414, Ley que establece los Derechos de las Personas Usuarias de los Servicios de Salud, aprobado por Decreto Supremo No 027-2015-SA, que establece: "Toda persona tiene derecho a obtener servicios, medicamentos y productos sanitarios adecuados y necesarios para prevenir, promover, conservar o restablecer su salud, según lo requiera la salud de la persona usuaria, de acuerdo a las guías de práctica clínica, el uso racional de los recursos y según la capacidad de oferta de la IPRESS y cobertura contratada (...). Mientras que, a nivel judicial, se le aperturó proceso por el delito contra la Vida, el Cuerpo y la Salud -Homicidio Culposo-.

En este caso, resulta evidente la forma cómo el tipo penal en blanco de "homicidio culposo" se colma con las normas técnicas establecidas en la Ley General de Salud. Si bien el Juez al momento que apertura proceso lo hace bajo la concepción de que se habría vulnerado el deber objetivo de cuidado, al inobservar las reglas de profesión (biomédica), lo que en efecto podemos advertir claramente, pues, el médico que finalmente atendió a la paciente, mostró una conducta desidiosa, una absoluta falta de interés o cuidado por la salud y la vida de la paciente y del feto; sin embargo, desde la perspectiva de la otra orilla, de la imputación objetiva, también encontramos fundamento seguro, resultando claro que el médico incrementó de forma innecesaria el riesgo permitido, al decidir que el parto sea vía vaginal y no por cesárea, como estaba prescrito cuando se revisaron las imágenes de la ecografía.

Caso $2^{32}$ : Este caso llegó a la Corte Suprema, donde se determinó que si existía responsabilidad penal de la imputada, en su calidad de enfermera, por el delito contra la Vida, el Cuerpo y la Salud, en su modalidad de Lesiones Graves Culposas, por inobservancia de reglas de profesión, en agravio del menor M.A.H.D. Veamos los detalles y la evidencia. Con fecha 02 de abril del 2009, a las 19:30 horas, aproximadamente, la acusada Guerra, en su condición de enfermera del Centro Médico de EESALUD -Cajamarca-, aplicó sin tomar los cuidados necesarios que requería la situación, un inyectable intramuscular en la zona del glúteo derecho del menor agraviado M.A.H.D., quien para entonces contaba con tan solo dos ańos cinco meses de edad, provocándole una lesión en el nervio ciático derecho en la parte del peroneo, la que a su vez le ha creado cojera del pie derecho. En cuanto a la acreditación fáctica, se señala en la ejecutoria suprema que la madre y el padre del menor fueron testigos presenciales de como la enfermera Guerra aplicó la inyección al menor agraviado. Asimismo, como prueba indirecta, tres testigos que se desempeñaban como enfermeras en el referido Centro Médico, señalaron que ese día la única que estuvo aplicando inyecciones en el tópico era la imputada. Los peritos que concurrieron al juicio oral señalaron que la lesión traumática del miembro ciático derecho fue a causa de una inyección intramuscular y/o aplicación de sustancia química en algún punto de la trayectoria del nervio ciático derecho. La imputada alegó como argumentos de descargos que no existe prueba directa ni indirecta que acredite que fuera la procesada recurrente quien aplicó la inyección al menor agraviado, pues si bien estuvo de guardia en el área de tópico de enfermería de la Red Asistencial EESALUD Cajamarca, en el mismo día había además una practicante, y que en el supuesto que haya sido quien colocó la inyección, ninguna de las sentencias precisan o prueban que la hubiera aplicado inobservando las reglas de profesión, aun cuando se considere pericialmente que

32. Sala Penal Permanente de la Corte Suprema de Justicia, Casación $N^{\circ} 182-2012$ Cajamarca, de fecha 15 de agosto de 2013. 
fuera por tal aplicación que se causó la lesión del nervio ciático del menor, pues no se puede inferir aquella conclusión únicamente del resultado lesivo; pues, agrega, que en algunos casos uno de los ramales del nervio ciático se extiende por el denominado cuadrante de seguridad, circunstancia que determinaría que cualquier inyectable aplicado a dicha zona ocasione de modo causal, pero fortuito, una lesión en el mencionado nervio, por lo que al no haberse acreditado que el menor no presenta una morfología particular de su nervio ciático, no puede presumirse que no la tenga $y$, por consiguiente, que se actuó con negligencia, sino que ello se debe a una concausa; ante lo cual se habría vulnerado el principio de legalidad, al no haberse acreditado uno de los elementos objetivos del tipo imprudente, esto es, la inobservancia de la regla de cuidado; entre otros argumentos. De igual modo, el Tercero Civilmente Responsable ESSALUD, también impugnó la sentencia alegando una indebida aplicación del artículo $90^{\circ}$ del Código Procesal Penal, al no haber sido debidamente concordado con los artículos $104^{\circ}$ y $105^{\circ}$ del Código Penal.

La Corte Suprema entendió que no se habría vulnerado el principio de legalidad, ni los principios de presunción de inocencia y adecuada motivación de las resoluciones; existiendo pruebas directas e indiciarias de la responsabilidad penal de la imputada, que fueron valoradas adecuadamente por el Tribunal de primera instancia y de apelación; y que lo que en realidad exigía la procesada, eran medios probatorios adicionales -a su juicio- de mayor certeza en sostén de la inferencia respecto a la mala praxis en la aplicación de la inyección, considerando que la única prueba admisible para acreditarla es una pericia médica que determine que la causa de la lesión pudo deberse a una desviación del nervio ciático del menor; lo que a juicio de la Corte Suprema, era una posición que partía del análisis de un caso excepcional no acreditado y poco probable, conforme lo indicó en el juicio oral una de las perito, particularidad que tampoco aparece advertida por ninguno de los especialistas que atendieron al menor con posterioridad a los hechos, y que en consecuencia, no se encuentra probado. Además, que al cuestionar el carácter incriminatorio de los elementos de prueba y su vinculación con los mismos -aspectos relacionados con la suficiencia de la actividad probatoria-, lo que está haciendo es una valoración de prueba que a través del recurso de casación no se puede provocar un nuevo examen crítico de los medios probatorios que sirvieron de base a la sentencia, en tanto en cuanto no es una tercera instancia y no constituye facultad de la Sala Casacional.

En este caso, no existe duda que se vulneró el deber objetivo de cuidado al aplicar una inyección intramuscular en la zona del glúteo sin la diligencia debida, inobservando así las reglas de profesión, lo que conllevó a que lesionara el nervio ciático del menor agraviado, lo que a su vez condujo que le produjera una cojera permanente de su pierna derecha.

\section{CONCLUSIONES}

1. La "infracción de un deber objetivo de cuidado", es una categoría dogmática con el cual se pretende evaluar si una conducta es culposa o no. Inicialmente se pensaba que la culpa se encontraba sistemáticamente al lado del dolo formando parte de la culpabilidad, sin embargo, Karl Engisch se 
encargó de delimitarla correctamente dentro de los elementos categoriales del delito al sostener que la lesión de la diligencia objetiva no pertenece a la culpabilidad, sino a la antijuridicidad.

2. Roxin se encarga de precisar un poco más la noción de "infracción de un deber objetivo de cuidado", al sostener que su interpretación sugiere de manera errónea la posición de un delito de omisión; cuando también asume una posición activa; y sustituye dicha categoría por los criterios de imputación objetiva; según el cual al sujeto no se le reprocha el haber omitido algo, sino el haber creado un peligro no amparado por riesgo permitido y sí abarcado por el fin de protección del tipo, que se ha realizado en un resultado típico.

3. Gimbernat Ordeig es otro autor que se ha encargado también delinear los alcances de la noción de "infracción de un deber objetivo de cuidado", proponiendo en su lugar el principio del "fin de protección de la norma”, con el cual ofrece una perspectiva normativa, y por ende restrictiva-teleológica, afirmando que imputable sólo lo es el resultado que es producto del riesgo que quiso prevenir la norma violada, no otro no abarcado por esa norma; lo que ha conllevado a que sea calificado como un principio extremadamente vago y poco útil.

4. En el caso de la infracción a la lex artis, su sola infracción no es por sí misma constitutiva de delito, sino que, además, es necesario verificar que esa infracción a la lex artis produzca un resultado lesivo para el bien jurídico. Para que la imprudencia médica sea penalmente relevante es necesario que en el tratamiento dispensado al paciente se incurra en conductas descuidadas o negligentes. Incluso hoy en día se admite que, si el procedimiento médico fue el adecuado, pero el paciente no fue debidamente informado sobre el tratamiento o los riesgos que la intervención implicaba, y se produce un resultado lesivo vinculado a la falta de dicha información, entonces incurre en delito culposo.

\section{REFERENCIAS}

- Audiencia Provincial de Las Palmas (Sección 1a). Sentencia núm. 257/2016; de fecha 20 de marzo de 2009.

- Bernate Ochoa, Francisco. Imputación Objetiva y responsabilidad penal médica. Bogotá D.C.: Universidad del Rosario, 2010.

- Convención europea de Derechos Humanos y Biomedicina de 1997 (“Convención de Oviedo”).

- Declaración sobre el Genoma Humano y los Derechos Humanos de 1997.

- Declaración Internacional sobre Datos Genéticos Humanos de 2003.

- Dal Dosso, Dario Alberto. "Teoría de la imputación objetiva”. Investigación para la evaluación final correspondiente a la VI edición del master propio en Derecho Penal. Universidad de Sevilla, octubre/noviembre 2011. 
- Gimbernat Ordeig, Enrique. “A vueltas con la imputación objetiva, la participación delictiva, la omisión impropia y el derecho penal de la culpabilidad". Nuevo Foro Penal, 82, enero-junio (2014): 83-133. https://doi.org/10.17230/nfp.10.82.3

- López García de la Serrana, Javier. "La valoración del daño por falta de consentimiento in formado en la práctica médica”. Revista Economist \& Jurist, (2010). Acceso el 01 de agosto del 2021, desde https://www.economistjurist.es/articulos-juridicos-destacados/lavaloracion-del-dano-por-falta-de-consentimiento-informado-en-la-practica-medica/

- $\quad$ Mazuelos Coello, Julio. "El delito imprudente en el Código penal peruano. La infracción del deber de cuidado como creación de un riesgo jurídicamente desaprobado y la previsibilidad individual". Portal Anuario de Derecho Penal, (2003). Acceso el 02 de agosto del 2021 desde https://perso.unifr.ch/derechopenal/assets/files/anuario/an_2003_09.pdf

- $\quad$ Primera Sala Penal Liquidadora de la Corte Superior de Justicia de Lima, Exp. 5120-2018.

- $\quad$ Roxin, Claus. Derecho penal, parte general, Tomo I. Fundamentos. La estructura de la teoría del delito. Traducción y notas Diego Manuel Luzón Peña. Miguel Díaz y Gracia Conllevo. Madrid: Civitas, 1997.

- Sala Penal Permanente de la Corte Suprema de Justicia, Casación No 182-2012 Cajamarca, de fecha 15 de agosto de 2013.

- Sala Penal Permanente de la Corte Suprema de Justicia, Casación N 581-2015 Piura.

- Sala Penal Permanente de la Corte Suprema de Justicia, Casación N 153-2017 Piura, de fecha 24-04-2018.

- Salinas Siccha, Ramiro. Derecho Penal. Parte Especial (Vol. 1). Lima: Grijley, 2010.

- Torio López, Ángel. “El deber objetivo de cuidado en los delitos culposos”. Anuario de derecho penal y ciencias penales, 27, 1 (1974): 25-59.

- Tribunal Supremo Español, Sentencia de la Sala de lo Civil del 8 de septiembre de 2015.

- Vázquez Ferreyra, Roberto. Daños y perjuicios en el ejercicio de la medicina (2o ed.). Buenos Aires: Hammurabi, 2002.

RECIBIDO: 20/09/2021

APROBADO: $25 / 11 / 2021$ 